\section{Differential gene expression of the three natriuretic peptides and natriuretic peptide receptor subtypes in human liver}

\author{
A M Vollmar, G Paumgartner, A L Gerbes
}

\begin{abstract}
Background-Various effects of atrial natriuretic peptide (ANP) on the liver have been observed. However, there is limited information about the types of receptors for natriuretic peptides expressed by the human liver.

Aim-To investigate gene expression of the three NP receptor types (NPR) as well as of the NP in human liver.

Methods-Presence of $\mathrm{mRNA}$ coding for all three NPR and for ANP, brain and C-type natriuretic peptide (BNP, CNP) was investigated by reverse transcriptionpolymerase chain reaction (RT-PCR). Human liver tissues and hepatocellular carcinoma tissues were examined.

Results-Specific PCR products for all three NPR, namely NPR-A, B, and C, could be detected. Moreover, ANP and CNP, but not BNP mRNA was detectable. The concentration of ANP transcripts was up to fivefold higher in hepatocellular carcinoma compared with non-tumorous liver tissue of the same subjects. No difference in the expression of NP receptors relative to GAPDH mRNA of tumorous and non-tumorous tissue was observed except of slightly increased NPR-A transcripts.

Conclusion-These data show that NPR transcripts are coexpressed with ANP and CNP mRNA in the human liver. This provides evidence for a local NP system in the human liver.
\end{abstract}

(Gut 1997; 40: 145-150)

Keywords: atrial natriuretic peptide, liver, gene expression.

Institute of

Toxicology and

Pharmacy,

Ludwigs-Maximilians-

University of Munich,

München, Germany

A M Vollmar

Department of

Medicine II,

Klinikum Grosshadern,

Ludwig-Maximilians-

Ludwig-Maximilians-
University of Munich

München, Germany

G Paumgartner

A L Gerbes

Professor Dr A M Vollmar,

Institut für Pharmakologie,

Toxikologie und Pharmazie,

Königinstr 16,

80539 München, Germany.

Accepted for publication

28 August 1996

(ANP) discovery of atrial natriuretic peptid (ANP) most of the studies with the cardiac hormone have focused on its renal and cardiovascular effects. ${ }^{12}$ However, there is increasing evidence for further biological effects of ANP. ${ }^{3}$ For instance ANP also seems to affect liver functions. A cytoprotective effect of the peptide on perfused liver against ischaemia and reperfusion injury has been demonstrated. ${ }^{4}$ Furthermore, ANP has been reported to prevent damage of isolated hepatocytes by oxygen radicals ${ }^{5}$ as well as to inhibit the growth of hepatoblastoma (HEP G2) cells. ${ }^{7}$ These effects of ANP on the liver seem to be mediated by specific receptors as suggested by increased particular guanylate cyclase activity in liver membranes after exposure to ANP. ${ }^{8}$ Further-
Correspondence to more, binding studies using radiolabelled ANP showed specific binding sites for ANP on rat liver membranes. ${ }^{9}$

Meanwhile two further natriuretic peptides have been identified, namely brain natriuretic peptide (BNP) ${ }^{10}$ and C-type natriuretic peptide (CNP). ${ }^{11}$ Whereas ANP and BNP show similar pharmacological profiles, ${ }^{2} \mathrm{CNP}$ differs. It elicits mainly vasodilatory rather than diuretic effects. $^{12}$ This difference in action may be explained by the existence of distinct receptor subtypes for NP and a different pattern of their distribution in the body. ${ }^{13} 14$ The natriuretic peptide receptor-A (NPR-A) is a membrane bound guanylate cyclase coupled receptor responding to both $\mathrm{ANP}$ and $\mathrm{BNP}$, but not to CNP. ${ }^{1315}$ A second guanylate cyclase coupled receptor, called NPR-B has been identified and seems to specifically bind CNP. ${ }^{16}$ The third receptor termed ANPR-C, is not linked to guanylyl cyclase and recognises all three NP.13 17

Up to now no information existed about possible effects of BNP and CNP on the liver, nor about the types of receptors for NP being expressed by the human liver. Therefore the aim of this study was to examine the presence of mRNAs coding for the NP receptors type A, $B$ as well as $C$ and the expression of the specific ligands within the liver, namely ANP, BNP, and CNP. Reverse transcription-polymerase chain reaction (RT-PCR) was used for this purpose.

In addition, as expression of ANP receptors has been demonstrated in a hepatoblastoma cells line ${ }^{7}$ tissue of hepatocellular carcinoma was included in the study. Differences in expression of NP receptors were examined by PCR. Quantification of mRNA levels for NP could be performed by means of competitive PCR using genomic DNA as competitor DNA. ${ }^{18}$

\section{Methods}

\section{Tissues}

The study was conducted according to the ethical guidelines of the declaration of Helsinki. Tumorous and non-tumorous liver tissue was obtained at surgery and immediately frozen in liquid nitrogen. Routine histology was performed on each specimen taken. Resection of hepatocellular carcinoma was performed in patient 1 (male, 67 years, no evidence for liver disease) and in patient 2 (male, 57 years, mild alcoholic cirrhosis (Child-Pugh grade A)). 
Histological examination showed a hepatocellular carcinoma with a low (patient 1) and with a medium degree of differentiation (patient 2), respectively.

\section{$m R N A$ extraction}

Total cytoplasmatic RNA of human liver tissue was extracted by the guanidinium-thiocyanate/ cesiumchloride method. ${ }^{19}$ The integrity of RNA preparations was confirmed by electrophoresis on agarose gels $(2 \cdot 5 \%)$. mRNA was isolated by adsorption of total RNA to oligo dT magnetic beads (PolyAtract Isolation System, Promega, Heidelberg, Germany) and quantified by ultraviolet adsorption.

\section{cDNA synthesis}

One $\mu \mathrm{g}$ mRNA was mixed with $\mathrm{p}(\mathrm{dT})$ 12-18 $(0.5 \mathrm{mg}), 20$ units of RNA ribonuclease inhibitor, $1 \mathrm{mM}$ desoxyribonucleotides (dNTP), $5 \mathrm{mM} \mathrm{MgCl}$ in $10 \mu \mathrm{l}$ transcription buffer (10 mM TRIS- $\mathrm{HCl}, 50 \mathrm{mM} \mathrm{KCl,} 0 \cdot 1 \%$ Triton $\times 100$ ) before adding $15 \mathrm{U}$ avian myeloblastosis virus reverse transcriptase (Reverse Transcription System Kit, Promega, Heidelberg, Germany) and incubating for 20 minutes at $42^{\circ} \mathrm{C}$. As previously described ${ }^{20}$ efficiency of transcription was estimated by incubating an aliquot $(4.5 \mu \mathrm{l})$ of the reaction mix with $1 \mu \mathrm{C}$ of $\left(\alpha-{ }^{32} \mathrm{P}\right)$ desoxycytosinetriphosphate (dCTP) $(3000 \mathrm{Ci} / \mathrm{mmol})$. Thereafter samples were heated $\left(95^{\circ} \mathrm{C}, 5 \mathrm{~min}\right)$ and then quickly chilled on ice. The amount of synthesised cDNA was estimated by the amount of $\left(\alpha-{ }^{32} P\right) d C T P$ incorporated, which was determined after separation of free dCTP. Separation was achieved by precipitation with trichloroacetic acid (TCA) (5\%) and filtration (glass fibre filters, $\mathrm{GF} / \mathrm{B}$, Whatman, Maidstone, UK). Efficiency of cDNA synthesis varied between $50 \%$ and $85 \%$. cDNA content of samples was equalised to $10 \mathrm{ng} / \mathrm{ml}$ in PCR buffer (20 mM TRIS- $\mathrm{HCl}$, pH 8.3, $50 \mathrm{mM} \mathrm{KCl}, 1.5 \mathrm{mM} \mathrm{MgCl}_{2}, 0.01 \%$ gelatin) and stored at $-20^{\circ} \mathrm{C}$.

Oligonucleotides used for PCR amplification Oligonucleotides purified by high performance liquid chromatography (HPLC) (MWG, Ebersberg, Germany) had the following sequences:

ANP (human gene $^{21}$ ) sense primer: 5'CAGCATGAGCTCCTTCTCCA-'3; antisense primer: 5'-TCCGCTCTGGGCTCCAATCCT-3' according to. ${ }^{22}$

BNP (human gene $^{23}$ ) sense primer: 5'TTCCTGGGAGGTCGTTCCCAC-3'; antisense primer: 5'-CATCTTCCTCCCAAAGCAGCC-3'.22

CNP (human gene ${ }^{24}$ ) sense primer: 5'-CGCACCATGCATCTCTCCCAGCTGCT-3'; antisense primer: 5'-CGCCGCACTAACATCCCAGGCCGC-3' according to. ${ }^{25}$

NPR-A (human gene ${ }^{15}$ ) sense primer: 5'-GGAGCGGACCCAGGCATACCTGGAGG-3'; antisense primer: 5'-AGGTCAGCCTCGGGTGCTACTC-3' modified after. ${ }^{26}$

NPR-B (human gene ${ }^{27}$ ) sense primer: 5'-GGTGGCACCAGCATATTGGACAAC-3'; anti- sense primer: 5'-TACAGGAGTCCAGGAGGTCCTT-3' modified after. ${ }^{26}$

NPR-C (human gene ${ }^{17}$ ) sense primer: 5'GTGGCCCGGCTTGCATCGCACTGG-3'; antisense primer: 5'-TCCGGATGGTGTCACTGCTC-3'. ${ }^{28}$

Glyceraldehyde-3-phosphate dehydrogenase (GAPDH) primers (human gene ${ }^{29}$ : 5'-TCCCTCAAGATTGTCAGCAA-3' and antisense 5'-AGATCCACAACGGATACATT-3' modified after. ${ }^{30}$

\section{Amplification method}

PCR was performed in PCR buffer $(100 \mu l)$ to which the following components (final concentration) were added: $50 \mu \mathrm{M}$ dNTPs, $1 \mathrm{nM}$ BSA, $0.1 \mathrm{mM}$ of each primer, $1 \mu \mathrm{Ci} \alpha-{ }^{32} \mathrm{P}-\mathrm{dCTP}$, two units of Taq DNA polymerase (Promega, Heidelberg, Germany), and various amounts of template DNA. The mixture was overlaid with mineral oil and subjected to 30 cycles for the NP and tubulin sequences and to 37 cycles for the NP receptor sequences. The amplification profile for the NP and GAPDH consisted of denaturation at $94^{\circ} \mathrm{C}$ for three minutes, primer annealing (at $59^{\circ} \mathrm{C}$ for NP and at $57^{\circ} \mathrm{C}$ for $\mathrm{GAPDH}$ ) for one minute, and extension at $74^{\circ} \mathrm{C}$ for three minutes (for six minutes after the last cycle). ${ }^{31}$ For the NP receptor mRNA amplification primer annealing was performed at $55^{\circ} \mathrm{C}$ for NPR-A and NPR-B, and of $57^{\circ} \mathrm{C}$ for NPR-C. In all experiments the presence of possible contaminants was tested by reactions in which either cDNA was omitted or mRNA was added instead of cDNA. To ensure that amplification of templates was exponential under the experimental conditions used, optimal conditions were elaborated for each template - that is, PCR with increasing amounts of initial templates as well as with increasing number of cycles were done. ${ }^{31}$

\section{Quantification of $P C R$ products}

For relative quantitation of NP PCR products we used the method of competitive PCR using genomic DNA as previously described in detail. ${ }^{20}{ }^{31}$ Briefly, a constant amount of cDNA (ANP $10 \mathrm{ng}$, BNP $100 \mathrm{ng}$, CNP $150 \mathrm{ng}$, respectively) and serial dilutions of competitor human genomic DNA (ANP 0.63-5 ng; BNP 0.63-10 ng; CNP 12.5-100 ng) were amplified. Aliquots of PCR products $(8 \mu \mathrm{l})$ were submitted to gel electrophoresis ( $6 \%$ acrylamide) and the DNA bands were identified by silver nitrate staining followed by exposure to $x$ ray films $\left(-70^{\circ} \mathrm{C}\right)$. The bands were cut into vials, dissolved in $30 \% \mathrm{H}_{2} \mathrm{O}_{2}$, and counted in a $\beta$ counter in the presence of scintillation fluid. PCR amplification of each sample was performed at least in duplicates and each experiment was repeated twice.

For comparison of NPR mRNA concentrations dose curves were performed to assess appropriate amounts of template for each of the three NPR-PCR as well as for the amplification of the GAPDH sequences. Similar efficiency of amplification of cDNA from 
normal and tumour tissue was shown by parallelity of respective dose curves. mRNA expression of the NPRs were evaluated by comparing PCR signals of tumorous and nontumorous tissues. To ensure similar amounts of initial cDNA mRNA of the house keeping gene GAPDH was amplified in a separate PCR. As lower initial concentrations of cDNA were mandatory for linear amplification of GAPDH transcripts compared with NPR mRNAs, GAPDH and NPR transcripts could not be coamplified. NPR signals were corrected referring to PCR signals for GAPDH sequences in both tissues. Samples were processed as described above. PCR amplification was performed in duplicate or triplicate and each experiment repeated twice.

\section{Results}

\section{Detection of $m R N A$ s coding for the NP receptor types}

A representative autoradiogram (Fig 1A) shows the presence of mRNA transcripts for all three NP receptors in the human liver. Various amounts of liver cDNA were amplified in the presence of the corresponding pairs of primers resulting in a 692,768 , and 378 bp signal for the $\mathrm{A}, \mathrm{B}$, and $\mathrm{C}$ receptor specific sequences, respectively. As control for possible contaminations, mRNA instead of cDNA was amplified in parallel and no DNA bands were visible after electrophoresis. cDNA from cells (rat C6-glioma) transfected with either human A or B receptor cDNA (provided by Prof Dr Gerzer, Köln) served as positive control.

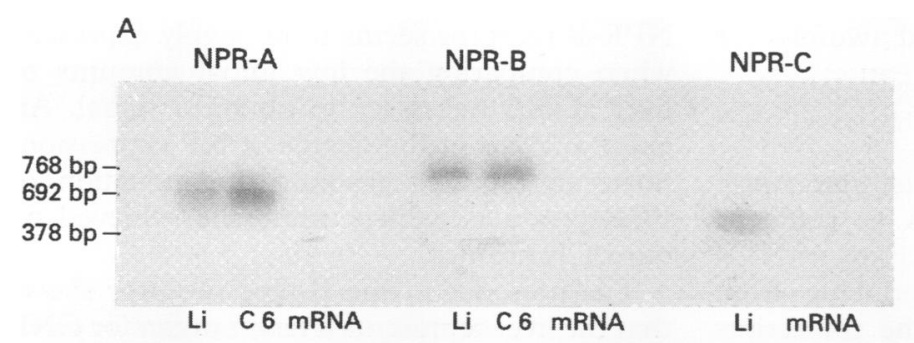

B ANP BNP CNP

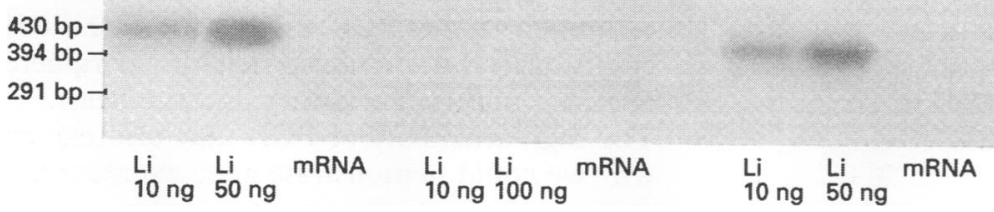

Figure 1: Representative PCR of $c D N A$ sequences of NP receptors $(A)$ and natriuretic peptides (B) in normal human liver tissue (patient 2). Corresponding amplification products were size fractionated by polyacrylamid gel electrophoresis and exposed to $\mathrm{x}$ ray films. cDNA were generated from normal human liver (Li). cDNA from transfected cells (C6) served as positive control and $m R N A$ from liver ( $m R N A$ ) was used as negative control. (A) NPR-A transcripts (692 bp); lane 1: liver cDNA (10 ng); lane 2: cDNA of NPR-A transfected cells $(0 \cdot 1 \mathrm{ng})$; lane 3: $m R N A(10 \mathrm{ng})$ from human liver. NPR-B transcripts (768 bp); lane 1: liver cDNA (2 ng); lane 2: cDNA of cells (C6) transfected with NPR-B cDNA (0.1 ng); lane 3: liver mRNA (2 ng); NPR-C transcript (378 bp); lane 1: liver cDNA (80 ng); lane 2: $m R N A$ (80 ng). (B) cDNA (10 ng, 50 ng) of human liver contains ANP transcripts (430 bp) as well as CNP specific sequences ( $394 \mathrm{bp})$, but no BNP transcript (291 bp) even at 100 ng initial cDNA input. Not reverse-transcribed $m R N A$ served as control for contamination and did not show any PCR products.
Demonstration of $m R N A$ transcripts coding for

the different NP

As shown in Figure 1(B) the specific ligands for the $A$ and $B$ type of NP receptors - that is, ANP and CNP were expressed in human liver tissue. In contrast, mRNA coding for BNP was not detectable. Amplification of cDNA (10 and $50 \mathrm{ng}$ each) using specific primers yielded a clear single band of $430 \mathrm{bp}$ for the ANP transcripts and a 394 bp comprising DNA fragment for CNP. No band was visible for BNP specific amplification (291 bp) even when higher amounts of cDNA (up to $100 \mathrm{ng}$ ) were used. When the PCR procedure was carried out in the absence of reverse transcriptase the corresponding bands were not seen, nor any other DNA fragments. This shows that the PCR products originate from $\mathrm{mRNA}$ and not from genomic DNA or another contamination. As the primers were designed to recognise sequences localised to different exons of the peptide genes, PCR transcripts from gDNA would be detectable by their different size (ANP: 533 bp; BNP: 522 bp; CNP: 838 bp).

\section{Comparison of NP gene expression in tumorous} and non-tumorous liver tissues

For the purpose of a relative quantification of mRNAs coding for NP competitive PCR analysis was performed. Figure 2(A) shows a representative experiment for amplification of

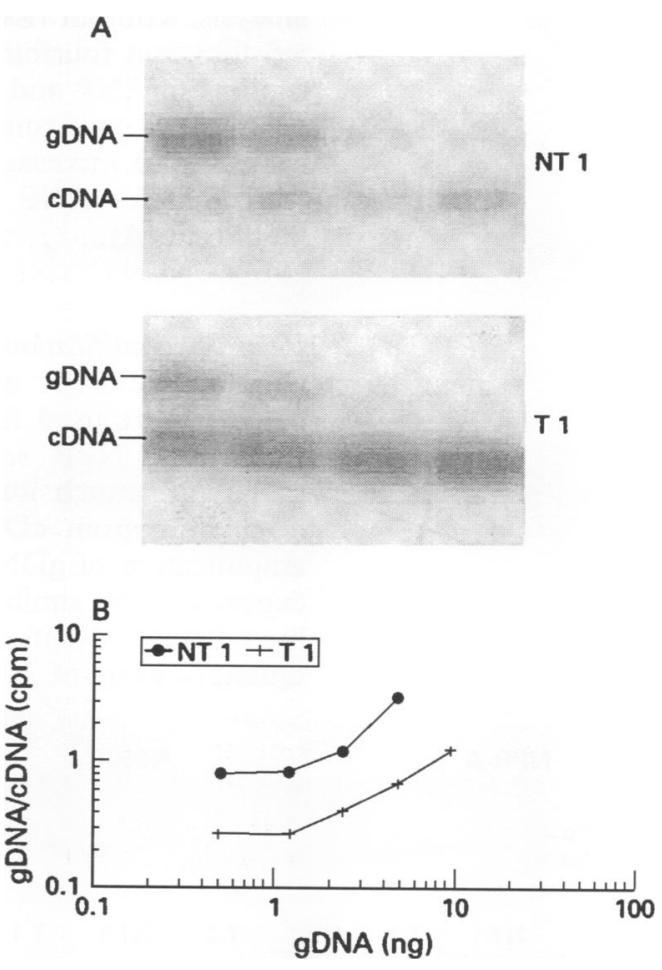

Figure 2: (A) Representative competitive PCR amplifying ANP specific templates of cDNA (10 ng) of non-tumorous (NT1) and tumorous liver tissue (T1). Decreasing amounts of $g D N A$ were coamplified (NT: 5-0.63 $n g: T: 10-0.63 \mathrm{ng}$ ). (B) Representative titration curves of $c D N A$ from nontumorous ( $\mathbf{\square}$ ) tumorous $(+)$ liver tissue for amplification of ANP sequences. Data were obtained by cutting the corresponding bands of PAGE gels visualised with silver nitrate $(A)$ and counting the radioactivity incorporated in the PCR products. The ratio of $g D N A / C D N A$ related radioactivity was plotted on a log-log scale against the amount of gDNA. 


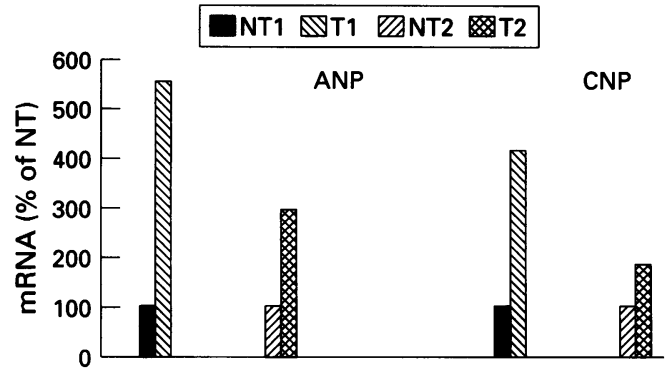

Figure 3: Relative ANP and CNP $m R N A$ levels in tumorous (T) and non-tumorous (NT) liver tissue of patient 1 and 2. Values (means) are derived from titration curves of two experiments performed in duplicate.

ANP sequences. A constant amount of cDNA is amplified together with serially decreasing amounts of standard gDNA. As the gDNA concentration decreases, the signal of the amplification product (533 bp) becomes less intense, and intensity of the target cDNA (430 bp) increases. Bands were cut, quantified by their amounts of radioactivity, and the PCR product ratios (gDNA/cDNA) were plotted as a function of the initial amount of gDNA (Fig 2(B)). Based on the equivalence region, where the PCR product ratio was around 1 , the shift towards the right of the curve obtained with cDNA from tumour tissue indicates an increased amount of PCR product. The principal set up for amplification of CNP sequences was the same as for ANP. Figure 3 summarises the results of competitive PCR analysis. Tumour tissue of patient 1 expressed 5.5-fold and fourfold higher mRNA concentrations of ANP and CNP, respectively, compared with non-tumorous tissue. Patient 2 showed also increased NP mRNA expression (threefold for ANP mRNA and twofold for CNP mRNA).

\section{Relative quantification of NP receptor transcripts} Competitive PCR using gDNA as standard could not be used for quantification of NPR transcripts. NPR sequences deducing from gDNA are much longer than the transcripts originating from cDNA. Thus, efficiency of amplification of gDNA and CDNA cannot be expected to be similar, which is a prerequisite for reliable quantification of PCR transcripts. Quantification of NPR transcripts has been

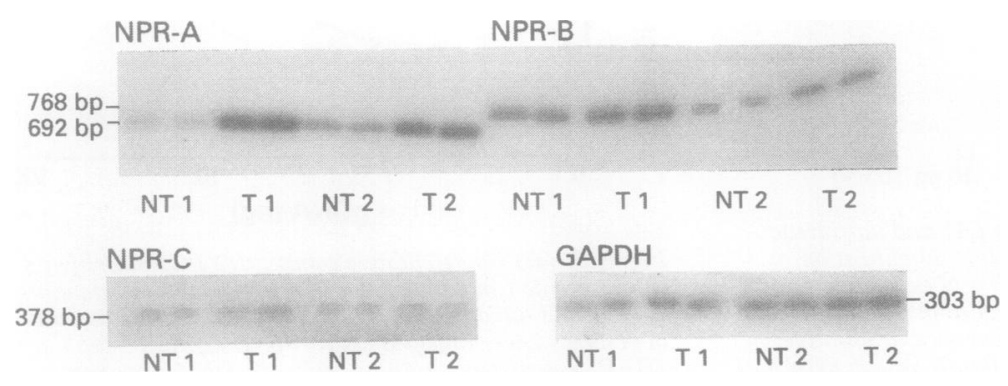
Figure 4: Comparison of NP receptor- and GAPDH transcripts in tumorous $(T)$ and non-
tumorous (NT) liver tissue of two patients $(1,2)$. NPR-A $(692 \mathrm{bp}),-B(768 \mathrm{bp})$, and $-C$ (378 bp) specific PCR products as well as GAPDH specific transcripts (303 bp) were separated by PAGE and further processed as described in Methods. For the amplification of $N P R-A,-B,-C$, and $G A P D H$ sequences $10,2,80$, and $0.05 n g c D N A$; respectively were used for amplification. achieved as follows: equal amounts of cDNA extracted from tumorous and non-tumorous tissue, which had been proved in previous experiments to be amplified in a linear mode, were subjected to PCR. The amount of amplified NP receptor fragments was evaluated by the amount of radioactive dCTP incorporated during the PCR procedure. In addition, expression of GAPDH mRNA was examined. GAPDH expression in normal liver was not significantly different from tumorous liver (range 90-120\%). In contrast, mRNA concentrations for tubulin, another 'house keeping gene', were increased up to twofold in the tumorous liver (data not shown). Therefore, the amounts of NPR transcripts were corrected for the respective GAPDH mRNA expression. Figure 4 shows a representative autoradiogram of receptor transcripts in tumorous liver and normal tissue. The Table summarises the quantification of the NPR-A, $-B$, and $-C$ mRNA in control and tumour tissue corrected relative to GAPDH expression. An increase of mRNA expression was present for the A-receptor (twofold) in patient 1. mRNA coding for the B-type and C-type receptor seemed not to be significantly changed in tumour tissue.

\section{Discussion}

Our data show the presence of specific mRNAs coding for the A-type as well as for the C-type of NP receptors in human liver. These findings extend previous reports of specific binding sites for ANP in the liver. ${ }^{5-9}$ Moreover, we detected expression of the B-type receptor in the liver, a novel finding. With regard to the relative level of expression of the three NP receptors, the NPR-B receptor seems to be highly expressed when comparing the low initial amounts of liver cDNA necessary to obtain a signal. An exact analysis of the degree of NP expression, however, requires absolute quantification of PCR products, which cannot be achieved by our PCR protocol.

The presence of the B-type receptor shows that the liver represents a target organ for CNP believed to be the specific ligand for NPR-B. Initially, this type of NP receptor together with its specific ligand CNP was thought to be restricted to the central nervous system, representing a local central natriuretic peptide system. ${ }^{11} 1632$ By means of a more sensitive technique such as PCR, mRNA for the NPR-B could also be demonstrated in peripheral organs - that is, the kidney and the heart. ${ }^{28} 33$ The high sensitivity of PCR may also explain why we could demonstrate gene expression of

$m R N A$ of different NPRs in hepatocellular carcinoma

\begin{tabular}{llr}
\hline & $T 1$ & $T 2$ \\
\hline NPR-A & $215(26)$ & $136(18)$ \\
NPR-B & $93(22)$ & $128(23)$ \\
NPR-C & $114(10)$ & $80(22)$ \\
\hline
\end{tabular}

mRNA concentration of NPRs in tumour tissue of two patients $(\mathrm{T} 1, \mathrm{~T} 2)$ expressed in \% of non-tumour tissue $(\mathrm{NT})$ of the levels. Data shown as mean (SEM). 
NP binding sites in the liver, whereas Wilcox et $a l^{14}$ using in situ hybridisation techniques did not observe NPR specific mRNAs in liver of primates.

It may be important to mention that some organs that exhibit NP receptors, express the specific NP ligands as well. ${ }^{29}{ }^{33-37}$ Therefore, the existence of local NP systems was suggested. For instance, the heart known to be the major site of ANP and BNP production, ${ }^{1-3}$ exhibits specific receptors for the NP. ${ }^{33}$ Recent data showed that CNP as well as its receptor, NPR-B are coexpressed in various tissues, such as kidney, heart, and chondrocytes. ${ }^{30} 333536$

Endogenous NP are thought to elicit paracrine or autocrine effects, or both, in these organs. For instance, in rat chondrocytes an autocrine regulation of cell proliferation by CNP and its receptor NPR-B has been shown. ${ }^{36}$

A similar hypothesis can be proposed for the liver based on our findings of ANP and CNP expression in addition to the presence of their specific NP receptors. The fact that BNP was not expressed in human liver deserves further attention. BNP exhibits similarities to ANP: both peptides share the heart as major site of synthesis as well as the pharmacological profile. ${ }^{12}$ In pathophysiological states, such as congestive heart failure or hypertension, however, BNP expression was affected to a different extent than ANP. ${ }^{34}{ }^{38}$ The presence of ANP, but not of BNP expression in the liver could further support the contention of different roles of these two NP.

We found increased expression of ANP in hepatocellular carcinoma. Similar findings were made for other tumours, for example, of the reproductive system. ${ }^{22}$ In this regard it is of interest that ANP elicits antiproliferative effects in various tissues including a hepatoblastoma cell line. ${ }^{7940}$ However, speculations about a local involvement of NP in tumour development clearly need further investigation. In this respect information on the type of liver cells expressing NPR and NP respectively, would be helpful. As NP receptors and NP have been described in vascular smooth muscle cells, epithelial and endothelial cells it has to be considered that transcripts originating from these cells might be detected using the highly sensitive PCR technique. However, there is evidence in the medical literature for the actual hepatocellular origin of NPR. Firstly, studies with isolated hepatocytes have shown that ANP elicits a dose dependent increase of cGMP indicating the presence of NPR-A receptors on hepatocytes. ${ }^{5} 6$ Secondly, binding experiments on whole liver tissue demonstrated the presence of functional NPR protein. ${ }^{9}$ Finally, studies on hepatoblastoma cells showed the presence of NPR-C. ${ }^{7}$ Thus, it seems reasonable to assume that the NPRmRNAs found in our study relate to liver specific cells. However, PCR analysis of the different separated liver cell populations could be a promising approach for further studies.

In conclusion, we have shown the presence of transcripts of all three NP receptors as well as of mRNAs coding for ANP and CNP in human liver. These data provide evidence for the existence of a local NP system in the human liver.

Prof Dr K W Jauch, Department of Surgery (head: Prof Dr Schildberg), Klinikum Großhadern, University of Munich, is thanked for providing tissue samples and Prof Dr R Gerzer Deutsche Forschungsanstalt für Luft und Raumfahrt, Cologne for providing the CDNA of cells transfected with NPR-A and NPR-B DNA. Drs Baretton, Wiebecke, and Zietz, Institute of Path B D. Drs Baretton, Wiebecke, and Zietz, Institute of Prof Dr Lohrs), University of Munich, undertook the histological examination of the tissues. We are gratefu to Ms A Wehlmeier for her excellent technical assistance. This (DFG, Vo 376/6-1 and Ge 576/13-2).

1 Brenner BM, Ballermann BJ, Gunnig GE, Zeidel ML. Diverse biological actions of atrial natriuretic peptide. Physiol Rev 1990; 70: 665-99.

2 Rosenzweig A, Seidman CE. Atrial natriuretic factor and related peptide hormones. Annu Rev Biochem 1991; 60 229-53.

3 Gutkowska J, Nemer M. Structure, expression, and function of atrial natriuretic factor in extraatrial tissues. function of atrial natriuretic
Endocr Rev 1989; 19: 519-36.

4 Bilzer M, Witthaut R, Paumgartner G, Gerbes AL. Prevention of ischemia/reperfusion injury in the rat liver by atrial natriuretic peptide. Gastroenterology 1994; 106: 143-51.

5 Pella R. The protective effect of atrial natriuretic peptide (ANP) on cells damaged by oxygen radicals is mediated through elevated cGMP-levels, reduction of calciuminflux and probably G-proteins. Biochem Biophys Res Commun 1991; 174: 549-55.

6 von Ruecker AA, Wild M, Rao GS, Bidlingmaier F. Atrial natriuretic peptide protects hepatocytes against damage
induced by hypoxia and reactive oxygen. Possible role of intracellular free ionized calcium. I Clin Chem Clin Biochem 1989; 27: 531-7.

7 Rashed HM, Sun H, Patel TB. Atrial natriuretic peptide inhibits growth of heptoblastoma (HEP G2) cells by inhibits growth of heptoblastoma (HEP G2) cells by
means of activation of clearance receptors. Hepatology means of activation

8 Waldman SA, Lewicki JA, Brandwein HJ, Murad F. Partial purification and characterization of particulate guanylate cyclase from rat liver after solubilization with trypsin. $\mathcal{F}$ Cyclic Nucleotide Res 1982; 8: 359-70.

9 Nair BG, Steinke L, Yu YM, Rashed HM, Seyer JM, Patel TB. Increase in the number of atrial natriuretic hormone receptors in regenerating rat liver. $f$ Biol Chem 1991; 266: 567-73.

10 Sudoh T, Kangawa K, Minamino N, Matsuo H. A new natriuretic peptide in porcine brain. Nature 1988; 332: 78-81.

11 Sudoh T, Minamino N, Kangawa K, Matsuo H. C-type natriuretic peptide (CNP): a new member of natriuretic natriuretic peptide (CNP): a new member of natriuretic peptide family identified in procine

12 Stingo AJ, Clavell AL, Aarhus LL, Burnett JC. Cardiovascular and renal actions of C-type natriuretic peptide. Am $\mathcal{F}$ Physiol 1992; 262: H308-12.

13 Nakao K, Ogawa S, Suga S, Imura H. Molecular biolog and biochemistry of the natriuretic peptide system. II Natriuretic peptide receptors. 7 Hypertension 1992; 10: 1111-5.

14 Wilcox JN, Augustine A, Goeddel DV, Lowe DG. Differential regional expression of three natriuretic peptide receptor genes within primate tissues. Mol Cell Biol 1991; 11: 3454-62.

15 Lowe DG, Chang MS, Helmiss R, Chen E, Singh S, Garbers DL, et al. Human atrial natriuretic peptide Garbers DL, et al. Human atrial natriuretic peptide receptor defines a new paradigm for second mess
signal transduction. $E M B O \Im 1989 ; 8: 1377-84$.

16 Koller KJ, Lowe DG, Bennett GL, Minamino N, Kangawa H, Matsuo $\mathrm{H}$, et al. Selective activation of the $\mathrm{B}$ natriuretic peptide receptor by C-type natriuretic peptide (CNP). Science 1991; 252: 120-3.

17 Porter JG, Arfsten A, Fuller F, Miller JA, Gregory LC, Lewicki JA. Isolation and functional expression of the human atrial natriuretic peptide clearance receptor cDNA. Biochem Biophys Res Commun 1990; 171: 796-803.

18 Gilliland G, Perrin S, Blanchard K, Bunn HF. Analysis of cytokine mRNA and DNA detection and quantitation by competitive polymerase chain reaction. Proc Natl Acad Sci competitive polymerase

19 Chirgwin JM, Przybyla AE, MacDonald RJ, Rutter WJ. Isolation of biologically active ribonucleic acid from Isolation of biologically active ribonucleic acid from
sources enriched in ribonuclease. Biochemistry 1979; 18: sources

20 Vollmar AM, Schulz R. Gene expression and secretion of atrial natriuretic peptide by murine macrophages. $\mathcal{F}$ Clin Invest 1994; 94: 539-45.

21 Nemer M, Chamberland M, Sirois D. Gene structure of human cardiac hormone precursor, pronatriodilatin. Nature 1984; 312: 654-6.

22 Gerbes AL, Gagnino L, Nguyen T, Nemer M. Transcription of brain natriuretic peptide and atrial natriuretic peptide genes in human tissues. $\mathrm{F}$ Clin Endocrinol Metab 1994; 78: 1307-11. 
23 Seilhammer J, Arfsten A, Miller JA, Lundquist $P$, Scarborough RM, Lewicki JA, et al. Human and canine gene homologs of procine brain natriuretic peptide. Biochem Biophys Res Commun 1989; 165: 650-8.

24 Tawaragi Y, Fuchimura K, Tanaka S, Minamino N, Kangawa K, Matsuo H. Gene and precursor structure of human C-type natriuretic peptide. Biochem Biophys Res Commun 1991; 175: 645-51.

25 Gerbes AL, Dagnino L, Nemer M. Detection of C-type natriuretic peptide compared with brain and atrial natriuretic peptide transcripts in human heart by polymerase chain reaction. Clin Investig 1993; 71: 672 .

26 Tremblay J, Huot C, Willenbrock RC, Bayard F, Gossard F Fujio N, et al. Increased cyclin guanosine monophosphate production and overexpression of atrial natriuretic production and overexpression of atrial natriuretic
peptide. A- receptor mRNA in spontaneously hyperpeptide. A- receptor mRNA in spontaneou
tensive rats. $\mathcal{F}$ Clin Invest 1993; 92: 2499-508.

27 Chang MS, Lowe DG, Lewis M, Hellmiss R, Chen $E$ Goeddel DV. Differential activation by atrial and brain natriuretic peptides of two different receptor guanylate cyclases. Nature 1989; 341: 68-71.

28 Canaan-Kühl S, Jamison RL, Myers BD, Pratt RE. Identification of $\mathrm{B}$ receptor for natriuretic peptide in human kidney. Endocrinology 1992; 130: 550-2.

29 Terada Y, Tomita K, Nonoguchi H, Yang T, Marumo F. PCR localization of C-type natriuretic peptide and B-type receptor mRNAs in rat nephron segments. $A m \mathcal{F}$ Physiol 1994; 267: F215-22.

30 Tso YJ, Sun XH, Kao T, Reece KS, Wu R. Isolation and characterization of rat and human glyceraldehyde3-phosphate dehydrogenase cDNAs: genomic complexity and molecular evolution of the gene. Nucleic Acids Res 1985; 13: 2485-502.

31 Vollmar AM, Schulz R. Coexpression and differentia regulation of natriuretic peptides, ANP, BNP, CNP in mouse macrophages. $\mathcal{F}$ Clin Invest 1995; 95: 2442-50.
32 Samson WK, Skala KD, Huang FLS. CNP-22 stimulates, rather than inhibits, water drinking in the rat: evidence for unique biological action of the C-type natriuretic peptides. Brain Res 1991; 568: 285-8.

33 Nunez DJR, Dickson MC, Brown MJ. Natriuretic peptide receptor mRNAs in the rat and human heart. $f$ Clin Invest 1992; 90: 1966-71.

34 Dagnino L, Lavigne JP, Nemer M. Increased transcript for B-type natriuretic peptide in spontaneously hypertensive rats. Quantitative polymerase chain reaction for atrial and brain natriuretic peptide transcripts. Hypertension 1992; 20: $690-700$

35 Vollmar AM, Gerbes AL, Nemer M, Schulz R. Detection of C-type natriuretic peptide (CNP) transcript in the rat heart and immune organs. Endocrinology 1993; 132: 1872-4.

36 Hagiwara $H$, Sakaguchi $H$, Itakura $M$, Yoshimoto $T$, Furuya $M$, Tanaka $S$, et al. Autocrine regulation of rat chondrocyte proliferation by natriuretic peptide $\mathrm{C}$ and its receptor, natriuretic peptide receptor-B. F Biol Chem 1994; 269: 10729-33.

37 Vollmar AM, Wolf $\mathbf{R}$, Schulz $\mathbf{R}$. Co-expression of the natriuretic peptides (ANP, BNP, CNP) and their receptors in normal and acutely involuted rat thymus. $\mathcal{f}$ Neuroimmunol 1995; 57: 117-27.

38 Wei CM, Heublein DM, Perrella MA, Lerman A Rodeheffer RJ, McGregor CGA, et al. Natriuretic peptide system in human heart failure. Circulation 1993; 88: system

39 Itoh H, Pratt RE, Ohno M, Dzau VJ. Atrial natriuretic polypeptide as a novel antigrowth factor of endothelial cells. Hypertension 1992; 19: 758-61.

40 Porter JG, Catalano R, McEnroe G, Lewicki JA, Protter AA. C-type natriuretic peptide inhibits growth factordependent DNA synthesis in smooth muscle cells. $A m \mathcal{F}$ Physiol 1992; 263: C1001-6. 